\title{
LAS ALTERNATIVAS EXISTENTES EN LA REALIZACIÓN DEL DERECHO A LA EDUCACIÓN EN LAS SOCIEDADES MULTICULTURALES
}

\author{
Antonio Tirso Ester Sánchez ${ }^{1}$
}

\begin{abstract}
Resumen
La realización del derecho a la educación deberá acomodarse a las condiciones estructurales de una sociedad que en nuestros días acentúa potencialmente su carácter multicultural. Son tres fundamentalmente las alternativas que en este contexto se presentan a la educación: el incremento del conocimiento, que mira a garantizar la mayor capacitación profesional por parte de los destinatarios del sistema educativo, la acomodación del educando a los valores sociales dominantes y la realización del libre desarrollo de la personalidad individual. Este trabajo pretende realizar un análisis del ideal que inspira la Declaración Universal de los Derechos Humanos en el ámbito educativo. Precisamente por ello, se debe garantizar que las políticas públicas educativas tengan en consideración la diversidad cultural impidiendo en todo caso que la cultura dominante limite el libre desarrollo de la personalidad de las minorías culturales.
\end{abstract}

Palabras clave: Multiculturalismo, Derecho a la educación, Libre desarrollo de la personalidad, Identidad cultural.

\section{PLANTEAMIENTO}

El concepto tradicional de educación ha ido transformándose hacia un nuevo enfoque influenciado por el fenómeno migratorio fruto de la globalización mundial que conlleva la confluencia de individuos culturalmente diversos procedentes de otros países y que ha obligado a reconstruir los sistemas educativos de forma progresiva, fundamentalmente en aquellas sociedades en donde se experimenta un acelerado crecimiento de población extranjera con culturas y tradiciones propias que pudieran entrar en colisión con el modo de pensar prevalente en las sociedades de acogida. Esta viene a constituir la causa principal por la que uno de los fines que tiene que lograr esta nueva visión educativa sea la construcción de una sociedad más plural, donde cohabiten ciudadanos con identidades culturales heterogéneas.

La multiculturalidad constituye, desde esta perspectiva, el contexto en el cual se va a desarrollar el programa educativo cuya acción deberá acomodarse lo máximo posible a dicha realidad sin resultar refractario al mismo. La educación a impartir dentro de este contexto presentará diferentes facetas. La mayor o menor atención

\footnotetext{
${ }^{1}$ Profesor Doctor del Área de Filosofía del Derecho adscrito al departamento de Ciencias Jurídicas Básicas. Facultad de Ciencias Jurídicas. Universidad de Las Palmas de Gran Canaria (España).E-mail: tirso.ester@ulpgc.es
} 
a cada una de ellas dará ciertamente un significado distinto al programa educativo. Lo que no conviene en ningún caso es que la atención a esa diversidad de facetas pudiera escorar su sentido haciendo perder de vista el fundamento último del propio acto educativo.

La perversión del sentido del proceso educativo constituye un peligro que hay que tener presente a fin de no dejarse llevar acomodaticiamente por la tendencia a consolidar, también a través del instrumento de conformación social que indiscutiblemente constituye la educación, situaciones de hecho arbitrarias, cuando no directamente discriminatorias de los propios destinatarios del proceso educativo. Se trataría en definitiva de preservar las facetas favorables desde el punto de vista de la realización individual, eliminando aquellas que supusieran una tergiversación del objetivo último que se ha de presuponer a la estructuración de ese proceso educativo.

La consideración de las distintas alternativas que muchas veces se pretenden compatibles entre sí nos permitirá esclarecer el motivo último de la educación, desestimando aquellas actitudes que tratan de colarse como un resultado natural del proceso educativo cuando en realidad representan el producto de una decisión arbitraria por parte de quienes ostentan el poder real en el grupo social de que se trate. Son tres fundamentalmente las alternativas que en el referido contexto multicultural se presentan a la educación: el incremento del conocimiento que mira a garantizar la mayor capacitación profesional por parte de los destinatarios del sistema educativo, la acomodación del educando a los valores sociales dominantes, que trata normalmente de presentarse bajo el subterfugio de hacer posible la integración social de los grupos minoritarios y la realización del libre desarrollo de la personalidad individual.

Obvio es decir que aunque estas tres opciones tratan de presentarse en ocasiones como opciones compatibles e incluso complementarias, su incompatibilidad salta en cualquier caso a la vista. Es necesario por ello, separar lo que tiene de bueno el sistema educativo, lo que habría que preservar a toda costa, de aquello que no hace más que degenerar el significado real de la educación, con miras a que el derecho a la educación cumpla la función liberadora que se le presupone. Analizaremos a continuación por separado las tres opciones referidas.

\section{EL INCREMENTO DEL CONOCIMIENTO}

La educación que reciben los individuos produce un incremento en sus conocimientos, ya que sirve de cauce para transmitir los valores, las costumbres y las tradiciones de las diferentes culturas. Esos valores asentarán las bases intelectuales del individuo que definirá y desarrollará su propia personalidad. Lo ideal sería que el propio individuo fuese consciente de que esos valores culturales que le han sido transmitidos no tienen por qué ser valores incuestionables, deberían constituir unas pautas previas para adquirir posteriormente un conocimiento sobre diferentes alternativas culturales, con la finalidad de lograr un conocimiento plural por parte del individuo 
que aprenda a discernir sobre lo que le conviene y sobre lo que le atrapa estableciendo cortocircuitos a su capacidad de elección autónoma para lograr una plena autonomía individual que le ayude a desarrollarse libremente como persona.

El individuo cuando sienta la necesidad de llevar a cabo determinadas prácticas culturales deberá realizarlas guiado por su propia razón y satisfacción, pero nunca sometido a las obligaciones que puedan imponerse por parte de los miembros del grupo cultural de pertenencia. La persona debe ser libre y hacer en todo momento lo que le dicte su propia moral (fuero interno) y sus convicciones asumiendo que sus actuaciones deberán respetar los derechos del resto de los integrantes de la sociedad, no pudiendo ir bajo ningún concepto en contra del libre desarrollo de la personalidad de los demás sujetos.

Cuando un progenitor influye en el menor para que realice determinadas prácticas culturales, lo hace bajo el convencimiento de que su realización constituye la mejor opción que se le presenta a su hijo, debido a que esta herencia cultural transmitida a través de las distintas generaciones ha marcado las pautas morales de sus antecesores. Pero esa buena intención no deberá constituir un freno para que el individuo, desde la posición que proporciona el mayor conocimiento de las diferentes opciones culturales pueda separarse de las pautas de comportamiento y del modo de pensar que prevalece en su propia tradición familiar.

Si un individuo solamente conoce los presupuestos de su propia cultura, podrá desarrollar una existencia totalmente digna, plena y autónoma desde la consideración de su propia y condicionada realización y concepción de vida. Pero la propia experiencia nos ha hecho comprender que el incremento del conocimiento de los rasgos definitorios de las demás culturas nos llevará a revisar muchas veces de manera contundente el significado de nuestros más intrínsecos valores culturales. Si exclusivamente conocemos una determinada cultura, viviremos felices a causa del desconocimiento de las demás, y por ende no seremos conscientes de las peculiaridades que nos ofrecen las diversas opciones culturales. En cambio, si a través del proceso educativo tenemos más perspectivas de análisis sobre las distintas culturas y formas de vida, ese conocimiento plural nos va a "enseñar a traicionar racionalmente en nombre de nuestra única verdadera pertenencia esencial, la humana, a lo que de excluyente, cerrado y maniático haya en nuestras afiliaciones accidentales, por acogedoras que éstas puedan ser para los espíritus comodones que no quieran cambiar de rutinas o buscarse conflictos"2.

Aunque resulta bastante difícil desprenderse de los condicionamientos culturales que se nos han inculcado a lo largo de todo nuestro proceso educativo dentro de un determinado contexto cultural que ha definido nuestra personalidad en base a unas creencias y unos preceptos morales propios de la cultura que, siendo menores, no hemos sido conscientes de haber elegido, sí podemos cuando menos llegar a un punto de inflexión con nuestros propios conocimientos y hacer más flexibles nuestros anclajes culturales desde la perspectiva que nos

\footnotetext{
${ }^{2}$ SAVATER, Fernando. El valor de educar. Barcelona: Ariel, 2008, p. 150.
} 
proporciona la información de la existencia de otras propuestas culturales de las que no tuvimos conocimiento en el marco que supuso el entorno cultural en que fuimos educados hasta conformar una personalidad propia y singular. La constancia de nuestra situación debería hacernos reflexionar acerca de la necesidad de mantener una actitud crítica con respecto a los procesos educativos que no hacen más que reproducir, sin que se haya producido la necesaria reflexión sobre el particular, las pautas establecidas por la cultura dominante.

Los poderes públicos tendrán que confeccionar políticas educativas ${ }^{3}$ que nos posibiliten un incremento de nuestro conocimiento de manera objetiva proporcionando información sobre todas las culturas con las que el hombre pudiera tener un posible contacto a lo largo de su vida, no solo con el objetivo de poder entender y conocer las prácticas culturales de los que le rodean, sino también para evitar el surgimiento de conflictos culturales que pueden llegar a ocasionar graves consecuencias negativas para la convivencia pacífica con los individuos que pudieran asumir el resto de las culturas existentes que se practican dentro de una determinada comunidad social.

A través de este conocimiento basado en la diversidad cultural, lo que se pretende garantizar es, por un lado, la preservación de la libertad propia de los individuos para poder adscribirse a unos u otros presupuestos culturales conformando lo más libremente posible su propia personalidad, y por otro, que tanto quienes comparten los presupuestos de la cultura dominante como quienes se adscriben a una cultura diferente a la hegemónica puedan llegar a comprender y conocer en mayor medida la peculiar idiosincrasia de los demás.

No podrá ser el mismo conocimiento ni la misma reflexión sobre las diversas ofertas culturales que pueden llegar a realizar los integrantes originarios de la sociedad de acogida que ven absolutamente respetada y valorada su identidad cultural, que el conocimiento y la autorreflexión que llevan a cabo aquellos sujetos que conforman las culturas minoritarias, y que, como tales, se plantean a toda costa, si es que logran resistir a la presión social que les conduce a acomodarse a las exigencias que tantas veces les impone la mayoría, la necesidad de asegurar el respeto a su idiosincrasia cultural a fin de lograr un desarrollo personal en igualdad de condiciones.

Los miembros pertenecientes a la sociedad mayoritaria ven asegurados sus presupuestos culturales y conocerán las diversas culturas de manera complementaria sirviéndoles para conocer diferentes perspectivas de la vida, y en ocasiones algunos miembros podrían ser atraídos por esas culturas y diferentes formas de vida, aunque en la mayoría de los casos, los miembros de la sociedad mayoritaria serán conscientes de que sus propias convicciones no eran tan firmes como creían. Esta reflexión que se puede llegar a hacer sobre sus propias convicciones, supondrá una posibilidad de libertad para una mayor realización personal.

\footnotetext{
${ }^{3}$ MUÑOZ ARNAU, Juan Antonio. Derechos y libertades en la política y la legislación educativas españolas. Navarra: Universidad de Navarra, 2010, p. 42, entiende por políticas educativas como aquellas "actividades estatales de gobierno - más o menos condicionadas por las acciones de los ciudadanos dirigidas a influirlas-, que, con base en las disposiciones constitucionales, tienen
} 
Los integrantes de las culturas minoritarias que conviven junto con los miembros originarios de la sociedad receptora verán siempre con un cierto recelo y desconfianza todos los medios y políticas que los poderes públicos pongan en marcha para difundir el conocimiento de las culturas ajenas a la cultura dominante. Son en buena medida conscientes de que la intención de quien detenta el poder y de quien pone en acción dichas políticas para garantizar el conocimiento plural y neutral de las diversas culturas no va precisamente encaminada a pintarlas de la manera más atractiva para que los propios miembros de la cultura dominante renuncien a ella. Es explicable esta desconfianza porque en el fondo la propia información cultural, por muy neutra que se pretenda se transmite siempre por parte de una persona que no puede dejar de estar inevitablemente condicionada por sus propios presupuestos culturales.

Ello no resta importancia al objetivo irrenunciable de intentar conseguir con la transmisión de dicha información cultural, que ha de ser transparente (porque de no ser así, de nada serviría la ejecución de dichas medidas), la liberación por parte de los individuos de los condicionamientos que lo limitan de manera que cada individuo pueda alcanzar una plena libertad en la formación de su voluntad y tome decisiones libres y autónomas que le ayudarán a conformar su propia identidad y su desarrollo personal. La consideración de los determinismos que pueda imponer una determinada situación de hecho no está reñida con el mantenimiento del objetivo social, por muy inalcanzable que éste pueda a la hora de la verdad resultar. Y es que siempre cabe realizar actuaciones encaminadas si no a conseguir el objetivo, si por lo menos a acercarse lo más posible a su realización.

La apertura cultural que se pretende alcanzar con la implantación de las políticas de conocimiento de la pluralidad cultural hacen posible que los sujetos no se aferren únicamente a los conocimientos culturales ya adquiridos, sino que les invita a conocer los valores y los modos de vida que ofrecen el resto de las diferentes alternativas culturales. Con ello se posibilita un mayor grado de entendimiento entre dichas culturas y se favorece un diálogo mucho más fluido entre los individuos que se adscriben a ellas, evitando el surgimiento de conflictos culturales que tantas guerras han protagonizado a lo largo de los siglos. Este tipo de actuaciones son llevadas frecuentemente a cabo por parte de las instituciones de aquellos Estados que enarbolan la bandera del pluralismo cultural.

Sería más factible hablar del incremento del conocimiento que nos soporta la educación dentro de los Estados democráticos, ya que este sistema de gobierno nos facilitará las herramientas suficientes para enjuiciar nuestros conocimientos y criterios. El sistema democrático aportará al proceso educativo una serie de ventajas que ayudarán considerablemente a fomentar el espíritu de autonomía crítica de cada individuo, así como a reforzar el valor inherente al diálogo frente a la imposición de las opiniones. Estas vienen a ser las mejores armas con las que

por objeto establecer las normas reguladoras de los procesos educativos, crear las instituciones correspondientes - o reconocer las de iniciativa social-y dotarlas de los medios personales y materiales, para satisfacer el derecho fundamental a la educación". 
cuenta el intelecto para seleccionar aquellas opciones que más nos aporten para el desarrollo de nuestra personalidad.

Cuando hablamos de que la educación sirve para incrementar el conocimiento de las personas se tiende a pensar (de manera errónea) que cuanta más información se le proporciona al individuo, éste tendrá un mayor conocimiento. No podemos, sin embargo, hablar de auténtico conocimiento cuando lo que se está haciendo en realidad es saturar al individuo de información y no se le ha dado tiempo para interiorizar y reflexionar suficientemente acerca de la información adquirida. Según Gimeno Sacristán, la información "pasa a ser conocimiento cuando tiene un sentido para quien lo adquiere; lo cual significa que ilumina algo nuevo, lo hace de otra forma o con un tipo de comprensión más profunda, lo que ya se conoce por experiencias previas. Es decir, se precisa engarzar la información proporcionada con la previamente existente, contextualizándola previamente”" Sólo en este contexto podríamos hablar de conocimiento en sentido estricto, cuando la información ha logrado sedimentarse experimentando un proceso de reflexión y crítica en el intelecto del individuo.

Estos conocimientos proporcionados a través de la educación no pueden quedar exclusivamente en manos de la educación privada. La educación no puede ser tratada como una mercancía o como un producto propio de las sociedades capitalistas reservado únicamente al alcance de las clases elitistas que cuentan con recursos económicos suficientes para disfrutar de ella. Para evitar esta situación, la educación pública tendrá entre sus objetivos garantizar al individuo un "saber cultural mínimo" para evitar que los alumnos caigan en una situación de marginalidad al carecer de estos saberes mínimos 5 .

La escuela debe tener una importancia clave en este sentido. Ya no puede ser considerada como un espacio destinado a transmitir a los alumnos una información destilada previamente por las instituciones públicas. El concepto de escuela evoluciona hacia una nueva definición al dotar de conocimiento a los alumnos y convertirse en un "espacio donde los alumnos puedan dar sentido, interpretar, contextualizar y criticar dicha información" ${ }^{6}$. En palabras del profesor Pérez de la Fuente, "el avance tecnológico y científico de los países occidentales ha permitido su mayor desarrollo social y económico, pero este hecho no puede ser interpretado en el sentido de desacreditar completamente el valor de otras culturas. En este sentido, una educación que incorpore otras visiones no es un producto empobrecido, sino que se corresponde más con el retrato de una realidad diversa de la condición humana"7.

\footnotetext{
${ }^{4}$ GIMENO SACRISTÁN, José. Educar y convivir en la cultura global: las exigencias de la ciudadanía. Madrid: Morata, 2001, p. 220.

${ }^{5}$ RUIZ ROMÁN, Cristóbal. Educación intercultural. Una visión crítica de la cultura. Barcelona: Octaedro, 2003, p. 124.

${ }^{6}$ Ibídem, p. 124.
} 
La consideración de ese avance tecnológico y científico obliga a tener en cuenta el papel que cumple la educación como instrumento más adecuado para el incremento de conocimientos técnicos. Esto es, como instrumento que potencia el incremento de aquellos conocimientos que a la hora de la verdad nos van a permitir resultar más competitivos en el mercado laboral. Resultaría absurdo despreciar el importante papel que también cumple la educación a este respecto.

El desarrollo de la personalidad es también, en muy amplia medida, el desarrollo de los talentos naturales y de las condiciones innatas de cada individuo, que lógicamente podrán potenciarse a través de la educación y es también la atribución de ciertos conocimientos que permitan compensar la inexistencia o la poca relevancia significativa de los talentos y condiciones que cada individuo pueda tener. Una educación que cierra los ojos ante la importante función que ha de cumplir con vistas a hacer profesionalmente más competitivo al educando será siempre catalogada en este sentido como una educación deficiente.

El individuo será desde luego tanto más auténtico, cuantas más posibilidades se le ofrezca en la definición de su propio ser, y estas serán lógicamente mayores cuantas más posibilidades tenga de competir con éxito incrementando el nivel de sus competencias y saberes técnicos. El éxito profesional permite aumentar significativamente la felicidad y la tranquilidad de espíritu al individuo al no tener que depender su situación vital de factores externos a su propio trabajo. Este es un factor relevante que en ningún caso debe ser desdeñado a la hora de organizar y poner en práctica los diferentes criterios educativos.

El problema radica en que la puesta de relieve de la indiscutible importancia de esos conocimientos técnicos lleva a ocultar el resto de funciones que ha de cumplir la educación. Se piensa así que la educación que permite incrementar adecuadamente los conocimientos técnicos del individuo agota en ello el papel que le corresponde. O, para ser más exactos, que cuanto mayor sean los conocimientos técnicos que proporciona mejor será la educación recibida.

Esta argumentación lleva a presentar como idóneo por excelencia un sistema educativo que, marginando cualquier tipo de consideraciones de índole valorativa, y en particular la consideración crítica acerca de los presupuestos culturales proyectados por la acción educativa, asegura la mayor competencia profesional del individuo. Llevada al extremo la argumentación referida tiende a ocultar el efecto de consolidación de la situación que puede provocar el hecho de centrar la atención en el mayor incremento de los conocimientos técnicos dejando intacta, como si no debiera ser objeto de ningún tipo de valoración crítica, a la desigualdad de condiciones en que a la hora de la verdad se encuentran los individuos para poder desarrollar libremente su propia personalidad al ver privados de reconocimiento a los presupuestos culturales que han sedimentado esa misma personalidad.

${ }^{7}$ PÉREZ DE LA FUENTE, Oscar. Pluralismo cultural y derechos de las minorías. Madrid: Dykinson, 2005, p. 392. 
Se corre igualmente el riesgo de absolutizar el valor de las culturas en las cuales el objetivo educativo que representa la consecución del mayor incremento de los conocimientos técnicos ha alcanzado su mayor realización, negando de este modo valor propio a otros sistemas culturales distintos. Es un riesgo que debe ser analizado con vistas a evitar el adoctrinamiento en contra de los valores que reconocen los derechos humanos.

Y es que con él, no se trata tanto de hacer más competente profesionalmente al individuo como de garantizar su libre desarrollo personal. Que la mayor competencia profesional puede contribuir en alguna medida a la realización individual es un hecho que no debe descuidarse, pero habrá de tenerse en cuenta que la capacitación profesional del individuo no es el único fin que ha de ser tomado en consideración, sino que, por el contrario, constituye un instrumento, de indiscutible valor, para la mejor realización de un objetivo más elevado.

Ante esta situación se hace necesario ubicar en su debida dimensión al papel que representa el incremento de los conocimientos técnicos que pudiera proporcionar el sistema educativo. Este constituye ciertamente una faceta que no debe ser en ningún caso descuidada a la hora de estructurar los procesos educativos. Pero es una faceta parcial cuya atención no puede descuidar el objetivo último que ha de cumplir la educación, que desde luego no se puede agotar en la garantía de la competencia profesional de quien la recibe.

La educación tiene por objeto poner a disposición del alumno "todos los elementos, conocimientos y perspectivas que le permitan elegir con plena libertad la respuesta a los estímulos externos para acrecentar constantemente la madurez de su conciencia, hasta alcanzar su pleno desarrollo como persona de acuerdo con su dignidad" ${ }^{8}$. Dentro de estos elementos y conocimientos ocupan un destacado lugar los conocimientos técnicos que garantizan una mayor competencia profesional del sujeto. Pero no serán éstos, los únicos conocimientos que han de tomarse en consideración, ni mucho menos servir de coartada para desestimar de manera irresponsable la valoración que cumple las consideraciones críticas en la propia conformación de la personalidad de cada uno.

No han faltado autores que en sentido contrario han venido a denunciar a los contextos culturales en los cuales se ha propagado en mayor medida esa absolutización del sentido de la educación como instrumento para la garantía del incremento de los conocimientos técnicos considerándolos como contextos en los que el sistema educativo se ve impedido para llevar a cabo su función más propia. En este sentido Bhikhu Parekh señala que "el contribuir al desarrollo de capacidades humanas tan valiosas como la curiosidad intelectual, la capacidad de autocrítica, la habilidad para sopesar argumentos y evidencias y formar juicios independientes; si es importante que cultivemos actitudes como la humildad moral e intelectual, el respeto a los demás y la sensibilidad ante distintos modos de vida y de pensar y que abramos las mentes de los estudiantes, el sistema educativo debe estar tan exento de eurocentrismo como sea humanamente posible".

\footnotetext{
${ }^{8}$ LLAMAZARES FERNÁNDEZ, Dionisio. Educación para la ciudadanía democrática y objeción de conciencia. Madrid: Dykinson, 2010, pp. 80-81.

${ }^{9}$ PAREKH, Bhikhu. Repensando el multiculturalismo. Barcelona: Itsmo, 2005, pp. 336-337.
} 
Este tipo de posiciones cumplen desde luego una importante función a la hora de relativizar el significado de la educación como un instrumento destinado a garantizar el incremento de los conocimientos técnicos por parte de los individuos. Pero tampoco deben llevarnos al extremo opuesto, esto es a negar cualquier valor a ese incremento de los conocimientos técnicos que contribuye a la mayor capacitación individual del individuo.

Tiene a este respecto razón León Olivé cuando señala que una persona bien educada "no sólo tiene información, conocimiento y habilidades para llevar a cabo tareas específicas en los mercados de trabajo: también cuenta con valores que ha hecho suyos críticamente y está dispuesta a revisarlos y redefinirlos, o bien, abandonarlos cuando lo considere pertinente. Sobre todo, tiene el hábito del pensamiento riguroso; destrezas necesarias para comprender, elaborar y criticar argumentos, y cautela frente a creencias y principios, en el imperativo de analizar sus fundamentos" ${ }^{10}$. Y es que en el fondo, el incremento de los conocimientos técnicos no resulta incompatible con la mejor realización del objetivo último del sistema educativo.

En este punto, el incremento de conocimientos con miras a la consecución de la mayor capacitación profesional ha de merecer un juicio muy distinto al que corresponde a la acomodación del educando a los valores sociales dominantes, que constituye, como antes indicábamos, la segunda alternativa que se suele presentar como objetivo de las políticas educativas.

\section{LA ACOMODACIÓN DEL EDUCANDO A LOS VALORES SOCIALES DOMINANTES}

Los procesos de enseñanza no se configuran como una "mera transmisión de conocimientos objetivos o de destrezas prácticas, sino que se acompaña de un ideal de vida y de un proyecto de sociedad" ${ }^{11}$. Por eso, a través de la educación se deben inculcar en los individuos una serie de valores universales comunes que posibiliten la realización de una convivencia pacífica y se logre integrar a los inmigrantes en las sociedades donde se han ido implantando. Esta situación sería la ideal, sin embargo existen culturas que por su trayectoria histórica no logran alcanzar la integración, precisamente porque los valores educativos asumidos e interiorizados ya de entrada suponen una agresión o lesión de daños a terceros.

El docente se convierte en un agente esencial para la transmisión del proyecto educativo unificado basado en los valores que la sociedad pretende transmitir al alumnado. Y entre esos valores universales comunes sobresale el respeto al derecho a la identidad cultural de cada individuo. El carácter universal de este derecho a la identidad cultural impone un contenido obligacional a los poderes públicos de la sociedad de acogida que deberán garantizar en la mayor medida posible su vigencia. Evidentemente el derecho a la identidad cultural quiebra cuando no se le permite al individuo realizar las manifestaciones que proyecta esa misma identidad

\footnotetext{
${ }^{10}$ OLIVÉ, León. Multiculturalismo y pluralismo. México: Paidós, 1999, pp. 26-27.

${ }^{11}$ SAVATER, Fernando. Op. cit., p. 133.
} 
cultural o cuando se intenta que el individuo acomode de manera forzada su comportamiento a unos presupuestos culturales que en principio le resultan ajenos.

La acomodación del comportamiento del inmigrante a los valores dominantes del grupo social en el que desarrolla su existencia puede suponer la pérdida o cuando menos la puesta en discusión de sus propios valores de identidad. Es por ello, por lo que al analizar el significado de la integración del sujeto en el país de acogida y su pleno desarrollo personal hay que tener en consideración los valores en clave de identidad cultural. No se trata de anteponer los valores propios de una cultura concreta a los valores específicos de la cultura dominante, sino más propiamente de entender que todos tenemos un idéntico derecho a la identidad cultural que se proyecta en la exigencia de respeto a los modos de vida y actitudes diferentes que proyectan una identidad cultural que, lógicamente no es ni puede ser común a todos ellos. El respeto a las manifestaciones diferentes de cada identidad cultural constituye una exigencia implícita a la vigencia del derecho universal, común a todos los individuos, a la identidad cultural.

Uno de los logros que debe ser alcanzado mediante la educación es la transmisión de valores e ideas de forma neutral respetando el pluralismo ideológico, la diversidad cultural y evitando bajo cualquier circunstancia el adoctrinamiento del alumnado, ya que este supone una vulneración de uno de los elementos clave del derecho a la educación como lo es la realización del libre desarrollo de la personalidad del educando. Por ello debe procurarse una educación basada en la objetividad (enseñando los valores y los sistemas culturales de la manera más aséptica posible), crítica (haciendo que el alumno se replantee el hecho de si determinadas prácticas culturales y tradicionales caben dentro de una sociedad que se entiende que ha de ser regida por el respeto a la dignidad y los derechos humanos) y pluralista (donde exista la posibilidad real de educar en la diversidad de ideas y opiniones siempre y cuando no se falte al respeto a los que tengan ideologías contrarias), y todo ello con la finalidad de alcanzar el pleno desarrollo de la personalidad del individuo.

¿Qué valores deberán transmitir las instituciones públicas de las sociedades dominantes en la educación a los ciudadanos?, ¿unos valores neutrales que darán un amplio margen a los sujetos para que se realicen a sí mismos conformando una auténtica sociedad plural?, o, ¿̇unos valores basados en los presupuestos definitorios de la cultura mayoritaria de dicha sociedad?. La respuesta a esta controvertida cuestión debería, en todo caso matizarse convenientemente. Se ha señalado por algunos estudiosos a este respecto que la neutralidad absoluta dentro de un sistema educativo podría llegar a resultar incluso hasta contraproducente, ya que el propio ideario de transmitir valores neutrales representa en sí mismo una concreta orientación ideológica dentro de la enseñanza.

La neutralidad que deberá promoverse en el complejo proceso que representa la educación será, en cualquier caso, aquella que evite condicionar el posicionamiento de los alumnos dentro de una determinada ideología, dentro de una confesión religiosa o dentro de alguna corriente filosófica. Se trata ante todo de garantizar 
la preservación de la libertad de opción del individuo, pero también de garantizar que nadie tenga poder suficiente para condicionar la pervivencia de esa misma libertad de opción de los demás.

La democratización de la enseñanza es definida por Xavier Besalú como "un fruto emblemático de la Modernidad y simboliza la lucha contra el oscurantismo y la superstición y la apuesta por el progreso de las personas y de las sociedades a través del conocimiento" ${ }^{12}$. En los sistemas democráticos, la neutralidad en el proceso educativo debería de ser relativa, no puede fomentarse dentro del alumnado posiciones neutrales en aquellas cuestiones que son trascendentales como son, entre otras, el racismo, el terrorismo, la corrupción política, la discriminación cultural, la defensa de las prestaciones sociales, etc., porque el desprecio a lo que significan estas mismas cuestiones constituye en sí mismo una indiscutible agresión a la libertad de opción de que también han de poder disfrutar los demás individuos.

La neutralidad que deberá presidir los sistemas democráticos, no tendrá que estar reñida con que se favorezca el pensamiento crítico del individuo. No puede ser neutral una enseñanza basada en la democracia, ya que "sería suicida que la escuela renunciase a formar ciudadanos demócratas, inconformistas pero conforme a lo que el marco democrático establece, inquietos por su destino personal pero no desconocedores de las exigencias armonizadoras de lo público" ${ }^{13}$. La democracia entendida en su significado más real, constituye el campo de juego inexcusable para poder plantearse la realización del objetivo último que representa el libre desarrollo de la personalidad.

El ideario educativo deberá estar fundamentado en los valores y los principios establecidos en la norma fundante de cada sociedad, respetando el modelo de sociedad elegido por sus ciudadanos, como lo es en el caso de nuestro país, que siendo un país democrático, siempre estarán determinados los valores por lo que diga la mayoría de la sociedad. Es por ello por lo que tenemos que conseguir alcanzar políticas públicas siempre dentro del respeto a la dignidad de las personas y sin vulnerar sus derechos individuales.

Habría, en este sentido, que tener en cuenta que el respeto al modelo de sociedad vigente lo debe ser a un modelo de sociedad en cuya conformación participen todos los individuos a través de una expresión de una voluntad que se haya formado libremente. Para ello es importante el papel que cumple el conocimiento de otros sistemas culturales diferentes al propio como instrumento de valoración crítica de la propia cultura identitaria. Pero este conocimiento que proporciona la educación debe ser igualmente respetuoso con el papel que cumple la cultura identitaria como soporte de la propia personalidad individual, evitando así la solución fácil que representa el acomodamiento de los individuos que participan de presupuestos culturales minoritarios a los presupuestos de la cultura hegemónica.

\footnotetext{
${ }^{12}$ BESALÚ, Xavier. Diversidad cultural y educación. Madrid: Síntesis, 2002, p. 34.

${ }^{13}$ SAVATER, Fernando. Op. cit., pp. 151-152.
} 
El Estado de Derecho democrático deberá preocuparse por formar críticamente a los ciudadanos inculcándoles los valores democráticos proclamados en sus respectivas Constituciones. Esta pretensión no significa que deba existir un monopolio educativo por parte del Estado, ya que también participan en el proceso educativo otros agentes sociales como lo son los padres y los profesores de los alumnos, que serán los responsables en igualdad de condiciones de que en dicho proceso no puedan darse contradicciones con las exigencias inherentes al respeto de los derechos humanos, con los valores constitucionales y con los principios que los padres y los profesores transmiten a sus hijos y alumnos respectivamente ${ }^{14}$. Pero los poderes públicos han de responsabilizarse de que la función educativa es llevada a cabo de manera efectiva, con toda la riqueza que se le supone, eludiendo la función condenable que muchas veces cumple como instrumento de perpetuación de la cultura hegemónica al acomodar a los alumnos a los presupuestos culturales mayoritariamente vigentes en el grupo social.

Existe un nexo evidente entre los valores y los derechos humanos. Los valores que fundamentan a los derechos humanos son los que tienen que ser transmitidos a través de la educación programada por las instituciones públicas. La perspectiva educativa de los derechos humanos "representa la expresión de una moral civil, con el contenido de una ética mínima, para una sociedad pluralista, democrática, cualquiera que sea la cosmovisión social, religiosa, ideológica o política” ${ }^{15}$.

Por un lado, deben transmitirse los valores imprescindibles que les permitan el desarrollo de una vida digna. Se trata de los valores que afectan a todos los individuos por igual. ¿Cuáles serían esos valores?. Según la Declaración Universal de los Derechos Humanos, se consideran como valores mínimos: la dignidad humana, el derecho a la vida, la libertad, la igualdad y la diferencia personal, la autoestima y la integridad. Expresión directa de estos valores es el derecho a la identidad cultural que quedaría directamente vulnerado si se utilizara el sistema educativo como un instrumento para la acomodación del individuo a los presupuestos de la cultura hegemónica. Es cierto que con ello desaparecería el conflicto cultural que tanta preocupación suscita en el marco social, pero ello se haría a costa de vulnerar el carácter universal del derecho a la identidad cultural. En definitiva se estaría en un caso semejante promoviendo un sistema educativo contradictorio con la filosofia de los derechos humanos.

La educación no puede ser considerada como un instrumento neutro porque adolece de una alta dosis de subjetividad al ser impartida por sujetos (para formar sujetos) que se encuentran inevitablemente influenciados por las tradiciones, las culturas, las leyes y los valores que conforman una determinada sociedad. Aunque lo que sí tienen que procurar los docentes es garantizar el respeto hacia las diferentes ideologías tanto de los propios alumnos como de sus progenitores, siendo esta misma sociedad la que perfila los ideales que conforman el sistema

\footnotetext{
${ }^{14}$ PECES - BARBA, Gregorio. Educación para la ciudadanía y Derechos Humanos. Madrid: Espasa, 2007, pp. 31-32.

${ }^{15}$ ALBERT GÓMEZ, María José. Derechos Humanos, Educación y Sociedad. Madrid: Centro de Estudios Ramón Areces, 2010, p. 112.
} 
educativo y que deben ser transmitidos para ser protegidos. Desde este prisma, nos debemos formular la siguiente pregunta: ¿Cuál debería ser el ideal básico que la educación tendría que fomentar? Fernando Savater defiende que el ideal que debe transmitir la educación es la "universalización democrática" ${ }^{16}$.

Por universalidad haremos referencia a dos aspectos. Por un lado, a la titularidad de los sujetos sobre los cuales recae el derecho a la educación ${ }^{17}$. La enseñanza tiene que procurarse en este sentido a todos los sujetos y no puede en ningún caso utilizarse como instrumento para discriminar a nadie. Ningún sujeto podrá ser excluido del proceso educativo ni encontrarse condicionado en el mismo por motivos raciales, sociales o culturales. Se pondrá especial atención a la protección en el ejercicio y la realización de este derecho de los menores de edad.

Uno de los propósitos de esta universalidad de la educación es "auxiliar las deficiencias del medio familiar y social en el que cada persona se ve obligado por azar a nacer, no refrendándolas como pretexto de exclusión” ${ }^{18}$; y por otro lado, asumir el hecho de que la universalidad proporciona al individuo un conocimiento exhaustivo sobre sus raíces culturales, ideológicas y políticas, siendo la educación un cauce para conocer su pasado y enraizarse en él, desechando las visiones diferentes a su identidad. Indiscutiblemente, el coste que implica este propósito que planteamos, no todos los gobiernos estarín dispuestos a asumir.

Este último enfoque de la universalidad del derecho no es del todo preciso en las sociedades actuales. Los avances sociales han superado con creces este aislamiento del individuo. Las raíces que hay que consolidar por medio de la educación son las de la "humanidad común", que son las que nos hacen ser a todas las personas la condición de humanos. En palabras de Fernando Savater, "nuestra humanidad común es necesaria para caracterizar lo verdaderamente único e irrepetible de nuestra condición, mientras que nuestra diversidad cultural es accidental” ${ }^{19}$, dado que no existen las culturas puras, todas las culturas están influenciadas las unas por las otras, y es esa mezcla entre culturas lo que puede denominarse "civilización", y es ésta, y no precisamente la cultura en sí misma considerada, la que debe ser transmitida a través del proceso educativo.

Este propósito de universalidad no encierra un intento etnocentrista que pueda considerarse sin mayores matices propios de las culturas occidentales, sino todo lo contrario, se trata de una tendencia que se pone de manifiesto en las culturas más aperturistas para luchar contra la impermeabilidad de algunas culturas. Este proceso

\footnotetext{
${ }^{16}$ SAVATER, Fernando. Op. cit., p. 141.

${ }^{17}$ La educación constituye un derecho reconocido universalmente de manera innata al individuo y que supone un elemento de carácter esencial para hacer posible el propio desarrollo de la persona y para la formación de una identidad propia. El derecho a la educación viene a ser entendido, en palabras de Alfred Fernández, "La educación como derecho cultural", Persona y Derecho, Vol. 50,2004 , p. 265, como un "empowerment right", es decir, como un derecho que de manera indirecta permite la realización del contenido obligacional de otros derechos diferentes que serán también a su vez imprescindibles para el desarrollo de la vida humana como lo son, entre otros, los ya reconocidos derechos civiles, políticos, económicos, sociales y culturales, cuyo ejercicio posibilitará a los individuos desfavorecidos competir en igualdad de condiciones y participar activamente en el funcionamiento de la vida social.

${ }^{18}$ SAVATER, Fernando. Op. cit., p. 145.

${ }^{19}$ Ibídem, pp. 147-148.
} 
liberalizador de las culturas a través de la educación supone desde luego todo un reto para los sistemas educativos democráticos. La educación se presenta en este sentido como "uno de los medios más importantes para la transmisión de valores de una generación a otra y debe, por tanto, jugar un importante papel en el cambio cultural requerido para abrazar los valores compatibles con el desarrollo" ${ }^{20}$.

Un objetivo principal de los proyectos educativos que se implantan en los Estados democráticos, es alcanzar la realización del libre desarrollo de la personalidad. Pero este libre desarrollo de la personalidad se llevará a cabo siempre dentro del marco y de las posibilidades que otorga la propia democracia, cuyos frenos son los derechos humanos, el respeto a la vida, la dignidad humana siempre en consonancia con nuestros valores constitucionales. Al margen de todo esto, el individuo podrá crear su propia forma de vida, siempre y cuando no afecte al libre desarrollo de la personalidad de terceros.

Gregorio Peces-Barba ha señalado que el debate existente acerca de los valores constitucionales, los derechos humanos, las instituciones del Estado de Derecho y de la democracia "no corre ningún peligro de distorsión ideológica si se lleva a cabo con libertad y rigor. Ese debate nunca puede ser visto como una discusión sobre la verdad filosófica, religiosa o científica, puesto que la sociedad tiene otros ámbitos para discutirla, sino como una reflexión acerca de las mejores, más justas y más correctas formas de organizar la convivencia humana"21. Y es que en el fondo de lo que se trata es de preservar la libertad del individuo intentando que el sistema educativo, lejos de constituir un freno a la misma constituya a través de la propia formación que suministra un instrumento que posibilite su mejor realización.

Se suele caer en el error de pensar que la educación de los ciudadanos basada en el espíritu de la Constitución del Estado consiste en que se lleven a cabo las acciones que los partidarios de la democracia convengan, pero la realidad debería ser que se llevarán a cabo aquellas acciones que permitan que la democracia sobreviva ${ }^{22}$. Difícilmente podría entenderse que una sociedad que trata de acomodar el sistema cultural de cada uno de los individuos a un patrón único resultara coherente con las exigencias que impone la democracia. Esta reclama la posibilidad de pensar, sentir y actuar de manera diferente, siempre que no se dañe con ello a los derechos de los demás.

Un sistema educativo que tuviera como objetivo el acomodamiento de los individuos a un determinado patrón cultural común menoscabando el ejercicio del derecho a la identidad cultural de cada individuo entraría en una contradicción directa con el ideal que representa la democracia. Esta presupone el protagonismo del individuo en la determinación de sus decisiones más relevantes. Y es a ello a lo que debe desde luego tender el

\footnotetext{
${ }^{20}$ DÍAZ-COUDER CABRAL, Ernesto. "Multiculturalismo y educación”. Cultura y representaciones sociales, año 4, núm. 7, sept. 2009 , p. 42.

${ }^{21}$ PECES-BARBA, Gregorio. Op. cit., p. 27.

${ }^{22}$ ARISTÓTELES, Política, trad. de C. García Gual y A. Pérez Jiménez, Madrid: Tecnos, 2008, pp. 329-330.
} 
sistema educativo en un régimen que quiera llamarse democrático. El libre desarrollo de la personalidad se impone en este sentido como una alternativa incompatible con la alternativa que reclaman los partidarios de instrumentalizar el sistema educativo para conseguir la mayor homogeneización social aniquilando las diferencias culturales que proporcionan a cada individuo su propia singularidad como tal.

\section{LA REALIZACIÓN DEL LIBRE DESARROLLO DE LA PERSONALIDAD}

El incremento del conocimiento con vistas a la consecución de una mayor capacitación profesional del individuo y la acomodación del mismo a los postulados definitorios de la cultura hegemónica en el territorio del que se trate representan alternativas que merecen un juicio evaluativo muy diferente. La primera alternativa es perfectamente defendible, porque precisamente por la capacitación profesional del individuo contribuye en buena medida a la mejor realización de su libertad y de su felicidad, puesto que le facilita considerablemente a alcanzar un determinado nivel de vida, despreocupándose en consecuencia a la hora de asumir sus opciones vitales de la necesidad de satisfacer sus necesidades de carácter subsistencial. La segunda constituye sin embargo una negación implícita de las posibilidades de desarrollo personal del individuo, ya que le priva del basamento natural para su desarrollo que constituye el respeto a los postulados definitorios de su cultura identitaria. Un individuo forzado a desprenderse de la cultura sobre la que ha ido configurando su personalidad se verá mucho más infeliz e inseguro en el establecimiento de sus relaciones sociales. Plantear la realización de este objetivo a través de una determinada estructuración del sistema educativo supone sin más desnaturalizar el sentido del derecho a la educación.

La educación se proyecta sobre individuos que normalmente no han alcanzado un grado de madurez suficiente para conformar opiniones sólidas y emitir juicios razonables sobre los problemas y cuestiones a que se enfrentan. Su objetivo debería ser precisamente garantizar que esos juicios y opiniones pudieran llevarse a cabo con un fundamento real, para servir a su vez de base a la propia andadura del individuo en el grupo social en el que habrá de moverse. En ese grupo social se le presentan al individuo diferentes opciones vitales, que debería en principio resolver por sí mismo, sin ayuda de nadie. Ese es sin duda el núcleo de la idea que representa el valor de la libertad. El individuo será tanto más libre en el desarrollo de su vida social cuanto más protagonista sea de sus decisiones, esto es, cuanto más respondan esas decisiones a un querer propio, no resultando dirigidas por otros miembros de la comunidad social.

El derecho a la educación es, en buena medida, el derecho que cada uno tiene a que se le proporcionen los instrumentos adecuados para poder decidir libremente en su entorno social. Esa libertad se proyecta por lo menos en dos vías diferentes. Constituye para empezar una libertad de decidir cuáles son nuestros propios intereses. Pero es también la libertad de decidir cuál es el procedimiento más adecuado para garantizarnos la realización de esos mismos intereses. 
El problema de la educación es que siendo un instrumento encaminado a la formación de un individuo protagonista de las decisiones relativas a la determinación de sus propios intereses y a la del procedimiento más adecuado para su realización, es un instrumento que le viene dado al individuo desde afuera. El individuo que recibe la educación no participa directamente de cuáles han de ser la estructura y los contenidos del sistema educativo.

El grupo social proporciona al individuo un instrumento orientado a la consecución de beneficios concretos para él mismo, pero lo hace sin contar para nada con él. Y, paradójicamente, se pretende que uno de los beneficios que proporciona la educación sea precisamente la garantía de la libertad y felicidad del sujeto, que difícilmente se van a poder alcanzar sin reconocerle al propio individuo el protagonismo que le corresponde en la toma de sus decisiones.

Se parte lógicamente de la base de considerar a la libertad como un valor superior del sistema social, entendiendo que las instituciones políticas y sociales, y también naturalmente las instituciones educativas, deberían orientar su funcionamiento a su mejor realización. El uso de la libertad puede no obstante ser razonablemente negado a un individuo que no dispone de la capacidad suficiente para tomar decisiones por sí mismo en la comunidad social. Es lo que sucede, por ejemplo, en el caso de la organización del sistema educativo. $\mathrm{Al}$ individuo se le proporciona una determinada educación sin preguntarle, al menos en el supuesto de la educación elemental, cuáles son los contenidos concretos que desea recibir, precisamente porque, por razones de edad o inmadurez, no dispone de la capacidad suficiente para poder tomar por sí mismo ese tipo de decisiones presentándolas como una proyección directa de su libre voluntad. Una función esencial del sistema educativo será desde luego intentar que el individuo salga de esa situación de incapacidad.

Las actitudes paternalistas se presentan normalmente como el remedio supuestamente razonable ante la situación de incapacidad que impide al individuo actuar por sí mismo en la determinación de sus intereses y del procedimiento más adecuado para su realización. Pero el paternalismo es siempre un sucedáneo de la libertad ${ }^{23}$. Por eso, el afán que muchas veces muestran las políticas públicas educativas de acomodar el modo de pensar de los individuos al modo que proyecta la cultura hegemónica en contradicción con los presupuestos definitorios de la cultura identitaria del individuo constituye no sólo una actitud paternalista, sino una actitud paternalista absolutamente injustificada porque no mira a salvar la incapacidad temporal del sujeto, sino a prolongarla indebidamente al privarle de un presupuesto fundamental para la propia elaboración de los juicios y opiniones sobre los que sustentará sus decisiones vitales.

\footnotetext{
${ }^{23}$ Asumimos la definición que da del paternalismo Gerald DWORKIN, “El paternalismo”. trad. de J. F. Malem Seña, en Jerónimo BETEGÓN, Juan Ramón DE PARAMO (dirección y coordinación), Derecho y moral. Ensayos analíticos. Barcelona: Ariel, 1990, p. 148, al entenderlo en un sentido amplio como "la interferencia en la libertad de acción de una persona justificada por razones que
} 
El paternalismo no constituye por consiguiente un fin en sí mismo. En su famoso ensayo Sobre la libertad, John Stuart Mill proponía la formulación de su principio de libertad con las siguientes palabras: "Que el único fin por el cual es justificable que la humanidad, individual o colectivamente, se entremeta en la libertad de acción de uno cualquiera de sus miembros, es la propia protección. Que la única finalidad por la cual el poder puede, con pleno derecho, ser ejercido sobre un miembro de una comunidad civilizada contra su voluntad, es evitar que perjudique a los demás. Su propio bien, físico o moral, no es justificación suficiente. Nadie puede ser obligado justificadamente a realizar o no realizar determinados actos porque eso fuera mejor para él, porque le haría feliz, porque en opinión de los demás, hacerlo sería más acertado o más justo. Estas son buenas razones para discutir, razonar y persuadirle, pero no para obligarle o causarle algún perjuicio si obra de manera diferente. Para justificar esto sería preciso pensar que la conducta de la que se trata de disuadirle producía un perjuicio a algún otro, la única parte de la conducta de cada uno por la que él es responsable ante la sociedad es la que se refiere a los demás. En la parte que le concierne meramente a él, su independencia es, de derecho absoluta. Sobre sí mismo, sobre su propio cuerpo y espíritu, el individuo es soberano"24.

Conforme a esta declaración las actitudes paternalistas de las políticas públicas quedarían descalificadas si entraran en contradicción con la posibilitación real del ejercicio de la autonomía individual. La educación se le proporciona a un individuo que no tiene capacidad suficiente para decidir por sí mismo, y se le proporciona un contenido educativo en cuya configuración no participa el sujeto afectado precisamente porque se trata con el de facilitar el acceso a esa capacidad que le permitirá actuar libremente por sí mismo.

Es evidente que los estados de minoría de edad o inmadurez justifican por sí solos este tipo de actuaciones paternalistas. El propio Stuart Mill lo expresa con mucha claridad inmediatamente después de la formulación de su principio de libertad ${ }^{25}$. Pero la actitud paternalista que se tenga en relación con estos individuos debería servir de instrumento y no de obstáculo para la propia realización del principio de libertad ${ }^{26}$. La configuración del sistema educativo es ese objetivo concreto y no ningún otro el que debe perseguir. Un objetivo que resulta plenamente compatible con el de proporcionar un incremento de conocimientos técnicos que le permita al individuo resultar en el futuro más competente a nivel profesional. Pero que de ninguna manera puede hacerse compatible con el objetivo, tantas veces puesto de manifiesto por determinadas políticas públicas de educación que carecen por completo de legitimidad, de acomodar el modo de ser y de pensar del individuo a los parámetros comunes establecidos por la cultura hegemónica.

se refieren exclusivamente al bienestar, al bien, a la felicidad, a las necesidades, a los intereses o a los valores de la persona coaccionada".

${ }^{24}$ MILL, John Stuart. Sobre la libertad. trad. de Pablo de Azcarate. Madrid: Alianza editorial, 1997, p. 68.

${ }^{25}$ Ibidem, pp. 68-69. 
Decir que la educación ha de mirar a la realización del principio del libre desarrollo de la personalidad no implica referirse única y exclusivamente al desarrollo de la personalidad del individuo que recibe esa misma formación. El principio del libre desarrollo de la personalidad tiene un carácter general, es extensivo a todos los individuos, y como tal prohíbe que ningún miembro del grupo social pueda atentar y plantear obstáculos ilegítimos a su realización ${ }^{27}$. Eso supone entender que el sistema educativo deberá organizarse de tal manera que se potencie al máximo la realización del libre desarrollo de la personalidad del estudiante, pero también la de los demás. Ello se hará mostrándole ante todo al propio estudiante que no ha de interferir de ninguna manera tampoco él en el libre desarrollo de la personalidad de los demás. Esa hipotética interferencia supondría ya directamente la realización por su parte de un daño a terceros que las instituciones públicas deberían poner todos los medios para evitar.

En este sentido, la estructuración del sistema educativo deberá hacer consciente al individuo del protagonismo que le ha de corresponder en la toma de las decisiones que afectan a la determinación de los intereses y de los medios más adecuados para realizarlos, proporcionarle instrumentos que le garanticen el mayor grado posible de libertad en la toma de esas mismas decisiones y hacerle comprender que no sólo debe ser el protagonista de sus decisiones, que también han de serlo los demás integrantes del grupo social. El sistema educativo no deberá perder de vista en ningún caso esta última apreciación inculcando en el individuo también actitudes de respeto hacia el valor que en sí mismo representa cada uno de sus semejantes por su misma condición de ser humano.

La educación deberá ciertamente ir orientada en este sentido a la realización del libre desarrollo de la personalidad estimulando el sentimiento de valor hacia sí mismo en quien recibe la educación, pero también el sentimiento de respeto hacia el valor de los demás, incitándole a ser tolerante con la expresión de los modos de pensar y actuar peculiares de cada uno. Ello es así no sólo, como muchas veces se ha querido ver, por la necesidad de evitar innecesarios conflictos sociales, sino sobre todo por la necesidad de reconocer a cada individuo la misma dignidad que a uno mismo le corresponde. En esta doble faceta, activa y pasiva, la realización del principio del libre desarrollo de la personalidad se presenta como el objetivo fundamental de las políticas públicas educativas.

\footnotetext{
${ }^{26}$ Como dice Ernesto GARZÓN VALDÉS, “¿Es éticamente justificable el paternalismo jurídico?”. en Doxa, núm. 5, 1989, p. 172, "sólo cuando la medida en cuestión... promueve o defiende su autonomía (del individuo) o aspira a la superación de un déficit de igualdad puede hablarse paternalismo éticamente justificado”.

${ }_{27}$ SANTANA RAMOS, Emilia. "Las claves interpretativas del libre desarrollo de la personalidad". Cuadernos electrónicos de Filosofía del Derecho, núm. 29, 2014, pp. 107-112.
} 


\title{
ALTERNATIVES IN THE ACTUAL REALIZATION OF THE RIGHT TO EDUCATION IN MULTICULTURAL SOCIETIES
}

\begin{abstract}
The realization of the right to education needs to be suited to the structural conditions of today's societies, where multiculturalism is emphasized. In this context, there are basically three alternatives that education may provide: Increasing knowledge, aimed to ensure the best career training for the end users of the educational system; the effective adoption of mainstream values by students, and the free realization of the development of the individual personality. This paper aims to analyse the ideal that inspire the Universal Declaration of Human Rights in education. For this reason, it must be ensured that public education policies take into account cultural diversity preventing the dominant culture limit the free development of the personality of cultural minorities.
\end{abstract}

Keywords: Multiculturalism. Right to education. Free development of personality. Cultural identity.

\section{REFERENCIAS BIBLIOGRÁFICAS}

ALBERT GÓMEZ, María José. Derechos Humanos, Educación y Sociedad. Madrid: Centro de Estudios Ramón Areces, 2010.

ARISTÓTELES, Política. Trad. de C. García Gual y A. Pérez Jiménez, Madrid: Tecnos, 2008.

BESALÚ, Xavier. Diversidad cultural y educación. Madrid: Síntesis, 2002.

DÍAZ-COUDER CABRAL, Ernesto. "Multiculturalismo y educación”. Cultura y representaciones sociales, año 4, núm. 7, sept. 2009.

DWORKIN, Gerald. "El paternalismo". trad. de J. F. Malem Seña, en Jerónimo BETEGÓN, Juan Ramón DE PARAMO (dirección y coordinación), Derecho y moral. Ensayos analíticos. Barcelona: Ariel, 1990.

FERNÁNDEZ, Alfred. “La educación como derecho cultural”. Persona y Derecho, Vol. 50, 2004.

GARZÓN VALDÉS, Ernesto. “EEs éticamente justificable el paternalismo jurídico?”. Doxa, núm. 5, 1989.

GIMENO SACRISTÁN, José. Educar y convivir en la cultura global: las exigencias de la ciudadanía. Madrid: Morata, 2001.

LLAMAZARES FERNÁNDEZ, Dionisio. Educación para la ciudadanía democrática y objeción de conciencia. Madrid: Dykinson, 2010.

MILL, John Stuart. Sobre la libertad. Trad. de Pablo de Azcarate. Madrid: Alianza editorial, 1997.

MUÑOZ ARNAU, Juan Antonio. Derechos y libertades en la política y la legislación educativas españolas. Navarra: Universidad de Navarra, 2010.

OLIVÉ, León. Multiculturalismo y pluralismo. México: Paidós, 1999. 
PAREKH, Bhikhu. Repensando el multiculturalismo. Barcelona: Istmo, 2005.

PECES-BARBA, Gregorio. Educación para la ciudadanía y Derechos Humanos. Madrid: Espasa, 2007.

PÉREZ DE LA FUENTE, Oscar. Pluralismo cultural y derechos de las minorías. Madrid: Dykinson, 2005.

RUIZ ROMÁN, Cristóbal. Educación intercultural. Una visión crítica de la cultura. Barcelona: Octaedro, 2003.

SANTANA RAMOS, Emilia. "Las claves interpretativas del libre desarrollo de la personalidad". Cuadernos electrónicos de Filosofía del Derecho, n. 29, 2014.

SAVATER, Fernando. El valor de educar. Barcelona: Ariel, 2008.

Trabalho enviado em 30 de março de 2016.

Aceito em 24 de agosto de 2016. 